\title{
104
}

Lechevalier, M. P. \& Lechevalier, H. (1957). J. gen. Microbiol. 104-111

\section{A New Genus of the Actinomycetales: Waksmania gen.nov.}

\author{
BY MARY P. LECHEVALIER \\ R.F.D. 1, Brookside Drive, Martinsville, New Jersey, U.S.A. \\ AND H. LECHEVALIER \\ Institute of Microbiology, Rutgers, The State University, \\ New Brunswick, New Jersey, U.S.A.
}

\begin{abstract}
SUMMARY: A single mesophilic species of a new genus belonging to the family Streptomycetaceae of the order Actinomycetales is described and has been named Waksmania ( $W$. rosea, type species). It produces a filamentous growth which is differentiated into vegetative (primary) mycelium and aerial (secondary) mycelium. Hyphae are $1.5 \mu$. or less in diameter. The new genus is characterized by the production of pairs of spores which are formed either: (1) at the tip of sporophores which branch from an aerially borne hypha; or (2) directly on an aerial hypha. Spores are not formed on the vegetative mycelium.
\end{abstract}

The micro-organisms commonly known as actinomycetes are thought by many to represent a group which is intermediate between the bacteria and the fungi. According to the most widely accepted systematic classification of these organisms, they are grouped under the order Actinomycetales (Bergey's Manual of Determinative Bacteriology, 1948). The organisms of the order Actinomycetales are described as those which form elongated cells which have a definite tendency to branch. Hyphae are $0.3-1.5 \mu$., usually about $1.0 \mu$. in diameter. Special 'fragmentation' spores, oidiospores, and conidia are formed by some genera. Briefly, the order is divided as follows (after Waksman \& Henrici, 1943):

Mycelium rudimentary or absent, no spores formed.

Family I. Mycobacteriaceae

(1) Sole genus: Mycobacterium

True mycelium produced.

A. Vegetative mycelium divides by segmentation into bacillary or coccoid elements.

Family II. Actinomycetaceae

(1) Anaerobic: Actinomyces

(2) Aerobic: Nocardia

B. Vegetative mycelium normally undivided.

Family III. Streptomycetaceae

(1) Conidia produced in aerial hyphae in chains: Streptomyces

(2) Conidia produced terminally and singly on short conidiophores :

Micromonospora 
Couch $(1949,1950,1954,1955)$ isolated some previously undescribed actinomycetes which form sporangia. In some strains, motile spores were enclosed in the sporangia (Actinoplanes); in others, non-motile spores were present (Streptosporangium). Couch proposed that these new genera be placed in a new family, Actinosporangiaceae. Waksman \& Corke (1953), in describing a new species of a thermophilic actinomycete, proposed the re-instatement of the genus Thermoactinomyces Tsiklinsky. Cultures of Thermoactinomyces are differentiated from the organisms of the genus Micromonospora, with which they had formerly been classified, by their ability to produce a true aerial mycelium, a characteristic which is lacking or appears in rudimentary form in Micromonospora spp. Thermoactinomyces spores are borne singly on sporophores on the vegetative and aerial mycelium. This genus would be classified under the family Streptomycetaceae.

The present paper reports the isolation of a new type of actinomycete which in some respects resembles Streptomyces and in others Micromonospora and Thermoactinomyces. This hitherto undescribed organism produces vegetative and aerial mycelium like Streptomyces and Thermoactinomyces. However, spores are formed in pairs, both directly on the aerial mycelium, and at the tip of sporophores which branch monopodially from a main aerial hypha. The name proposed for this new genus is Waksmania. The type species is W. rosea.

\section{METHODS}

\section{Isolation}

While examining a number of soils by using a slight modification of Couch's chytrid-isolating method (1939), a pink mycelial mass growing above the surface of the water on a particle of soil was observed. Following isolation to pure culture, this organism was found to have certain novel and previously undescribed characteristics.

Couch's method, as used here, may be described as follows : a scant teaspoonful of soil is placed in a sterile Petri dish and the dish flooded with sterile tap water. When the particles of soil have settled, several blades of grass, previously boiled for $15 \mathrm{~min}$., are placed on, or just beneath the surface of, the water, and the plate is incubated at $28^{\circ}$ for 1-5 weeks. Organisms growing on the grass and soil particles are observed and transferred with a sterile inoculating needle to a sterile agar medium, with the aid of a low-power objective.

\section{Media for characterization}

All media other than those described here are listed in Waksman's book on actinomycetes (1950). All complex organic constituents were products of Difco Laboratories (Detroit 1, Michigan, U.S.A.), except where otherwise noted. The soluble starch was a product of Merck and Co. Inc. (Rahway, New Jersey, U.S.A.).

Rice extract agar. Brown rice (River Brand Mills, New York, New York, U.S.A.) $200 \cdot 0$ g.; tap water, 1 l. agar, 15.0 g. Autoclave rice and water at $15 \mathrm{lb}$./sq. in. for $15 \mathrm{~min}$. Add $750 \mathrm{ml}$. hot water while rice is still hot, stir for 
1 min., decant and filter through cotton. Add agar. Do not adjust $\mathrm{pH}$ value.

Pablum extract agar. Pablum Mixed Cereal (Pablum Products, Div. of Mead, Johnson and Co., Evansville 21, Indiana, U.S.A.), 60.0 g.; tap water, 1 l.; agar, $15.0 \mathrm{~g}$. Place dry cereal in four fine cheesecloth bags and tie with strings. Dip bags up and down in boiling water for 2-3 min. Extract will be brownish and slightly viscous. Drain excess moisture from bags and discard. Add agar to extract, bring up to $1 \mathrm{l}$. Do not adjust $\mathrm{pH}$ value.

Oatmeal agar. Rolled oats, 70.0 g.; tap water, 11 .; agar, $15.0 \mathrm{~g}$. Boil oats in water for $5 \mathrm{~min}$., filter through fine cheesecloth, bring volume up to $1 \mathrm{l}$. while hot. Do not adjust $\mathrm{pH}$ value.

Gelatin. $12 \%(\mathrm{w} / \mathrm{v})$ in water.

Litmus milk. $105 \mathrm{~g}$. prepared powder (100 g. skim milk; 5.0 g. litmus) in 11. distilled water.

Potato agar. Prepared pills. 1 pill for $10 \mathrm{ml}$. medium. (Ben Venu Laboratory Inc., Bedford, Ohio, U.S.A.)

Nitrate broth. Peptone, 5.0 g.; beef extract, 3.0 g.; $\mathrm{KNO}_{3}$, $1.0 \mathrm{~g}$; d distilled water, 11 .

Carbon-free medium for testing cellulose utilization. $\mathrm{K}_{2} \mathrm{HPO}_{4}, 1 \cdot 0 \mathrm{~g} . ; \mathrm{NaNO}_{3}$, $0.5 \mathrm{~g}$.; $\mathrm{MgSO}_{4} .7 \mathrm{H}_{2} \mathrm{O}, 0.5 \mathrm{~g}$.; $\mathrm{KCl}, 0.5 \mathrm{~g}$.; $\mathrm{FeSO}_{4} .7 \mathrm{H}_{2} \mathrm{O}, 0.01 \mathrm{~g}$.; distilled water to 1 litre, $\mathrm{pH}$ value adjusted to $7 \cdot 5$. Strips of filter-paper are added to the tubes before sterilization.

All media were sterilized for $15 \mathrm{~min}$. at $15 \mathrm{lb} . / \mathrm{sq}$. in.

\section{Tests for antibiotic properties}

All the methods used were as described by Waksman (1950).

\section{Stains}

All staining procedures and solutions will be found in the Manual of Methods for Pure Culture Study of Bacteria (1951). Methylene blue $2 \%$ aqueous solution (w/v); Acid-fast stain Ziehl-Neelsen method, slides being decolorized for 1, 5, and 10 sec.; Gram method, Hucker's modification; Safranin as given in Hucker's modification of the Gram method; Crystal violet, Hucker's modification.

\section{Photographs}

Photographs were taken through a trinocular American Optical 'Microstar' microscope with a $35 \mathrm{~mm}$. Kodak photomicrography attachment. Microfile film (Eastman Kodak, Rochester, New York, U.S.A.) was developed in Kodak Mikrodol developer. Positives were made on Varigram paper (E. I. Du Pont de Nemours and Co. Inc., Wilmington 98, Delaware, U.S.A.), using appropriate filters. Electron photomicrographs were taken through an RCA EMU-1 electron microscope. Collodion films mounted on a grid were touched to the surface of a heavily sporulating agar culture, portions of the aerial mycelium becoming attached to the collodion membrane. Shadowing, when done, was with germanium at an angle of $26^{\circ}$. 


\title{
RESULTS
}

\author{
Waksmania Lechevalier et Lechevalier, gen.nov.
}

Fine mycelium (about $1 \mu$. in diameter) which is differentiated into (1) primary (vegetative) mycelium which grows into, and forms a compact layer on top of, agar media, and (2) secondary (aerial) mycelium which arises from the primary mycelium but grows into the air, away from the agar surface. The primary mycelium does not bear spores of any type; the secondary mycelium bears spores which are formed in longitudinal pairs. The spores are produced either directly on the aerial hyphae or on sporophores which branch from the aerial hyphae.

Type species, Waksmania rosea, Lechevalier et Lechevalier, sp.nov.

\section{Morphology}

Vegetative mycelium. $0 \cdot 3-1 \cdot 2 \mu$. in diameter. Filaments long, branching, penetrating the agar medium and forming compact, tough colonies like those of Streptomyces. Hyphae do not segment, even in old cultures.

Aerial mycelium. 0.8-1.5 $\mu$., usually about $1.0 \mu$., in diameter. Older hyphae tend to shrink in diameter. Some branching. Length of hyphae usually does not exceed $150 \mu$. Hyphae are not erect, but lie along the surface of the medium, or at less than right angles to it. Occasionally, an aerial hypha will arise from the agar, grow along the surface for some time, bear spores, and then the growing tip will dip again under the surface. 'Fairy rings', or alternating areas of aerial mycelium with zones having none, common to other members of the Streptomycetaceae, occur on some media. 'Coremia-like' aggregations of aerial hyphae are formed on a variety of substrates.

Sporophores. Small branchlets are formed monopodially in respect to the main axis of the aerial sporogenous hyphae. Spores are borne at the tip of these branchlets or sporophores. Sporophore diameter varies from 0.3 to $\mathbf{2 \cdot 0} \mu$. This wider dimension represents that of the base of a sporophore such as illustrated in Fig. 1B. Length varies from almost negligible to $6.0 \mu$., and is usually $1 \cdot 0 \mu$. or less. The sporophore does not appear to be cut off by a crosswall from the main hypha ( $\mathrm{Pl} .1$, figs. 8-10), and does not differ from it in appearance, except in diameter. Electron photographs also seem to reveal the presence of a cup or ring at the base of the spores borne on sporophores (Pl. 1, fig. 6). This detail is not apparent when the organism is viewed through the light microscope and may be an artifact.

Spores. Spherical to subglobose, $1 \cdot 5-2 \cdot 0 \mu$, usually about $1 \cdot 7-1 \cdot 8 \mu$. Spores are borne terminally on sporophores (Fig. 1C), as well as at the tips of the main sporogenous hyphae and branches (Fig. 2G). They are also borne directly on the sporogenous hyphae (Fig. 1A). Spores are formed in pairs, and when mature, are very easily detached from the sporophore and each other. Spores are sometimes borne eccentrically at the tip of the sporophore (Fig. 1D). None is formed on the vegetative hyphae, but occasionally the fall of an aerial filament into the agar will give rise to the impression that the spores are formed under the agar surface. Spore surface is smooth (Pl. 1, fig. 7). 
Spore formation. A tiny bud on an aerial hypha grows to form a small branchlet (Pl. 1, fig. 8), which then appears to develop two 'septa'. The protoplasm of the portion of the branchlet destined to become spores becomes more re-fractile to light than the portion destined to become the sporophore. Stained preparations (Pl. 1, figs. 3-5) seem to indicate the presence of septa

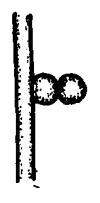

A

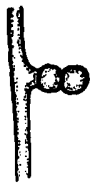

B

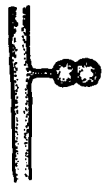

C

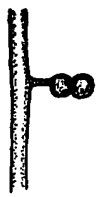

D

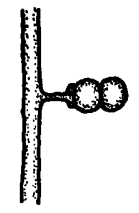

E

Fig. 1. Waksmania rosea. Spores borne: A, directly on the hypha; B, on a short sporophore; $C$, on a long sporophore; $D$, eccentrically on the sporophore; $E$, possible cup-shaped structure of the sporophore as suggested by electron microphotography.

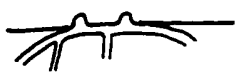

A

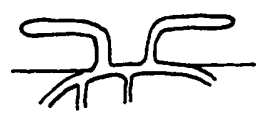

C

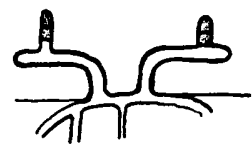

E
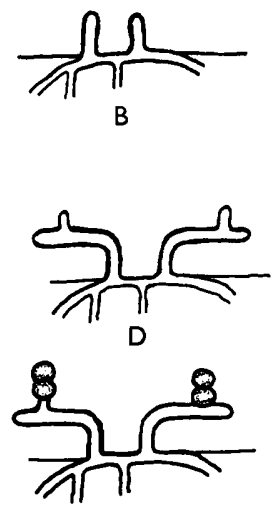

$\mathrm{F}$

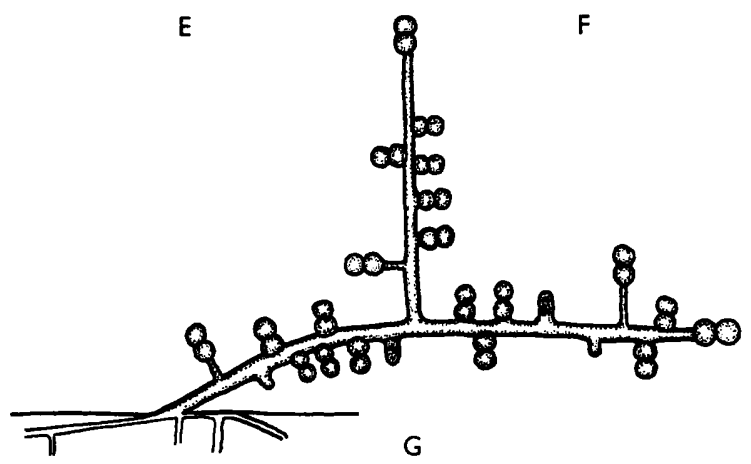

Fig. 2. Waksmania rosea. Schematic representation of the mode of formation of the aerial mycelium and spores. A, B, C, formation of aerial mycelium; D, E, F, formation of spores, one sessile and one with sporophore. At $\mathbf{E}$ note the condensation of the protoplasm of the future spore; $G$, schematic diagram of typical aerial hypha.

between spores; however, electron microphotographs do not confirm the presence of any cell wall (Pl. 1, figs. 7, 8). Both spores swell, not always simultaneously, and become more or less round (Fig. 2). On inoculation into 
a fresh medium the spores germinate, producing one to three germ tubes. A very large number of spores never germinate.

Appearance on various media

All cultures were incubated at $28^{\circ}$. Waksmania rosea does not form a soluble pigment on any medium tested.

Yeast glucose agar. White-tan glistening growth becoming dark brown and convoluted. Aerial mycelium is not formed.

Glucose asparagine agar. Growth meagre, colourless. Aerial mycelium is not formed.

Czapek's agar. Thin yellowish white growth. Scant aerial mycelium. Some malformed spores formed.

Rice extract agar. Bright orange pink vegetative mycelium. White aerial mycelium with light pink spores borne profusely. Strong earthy odour.

Pablum extract agar. Shiny bright pink-orange to brown-orange vegetative mycelium becoming covered with white aerial mycelium. Pink spores borne in profusion. Earthy odour.

Oatmeal agar. Orange-pink vegetative growth. White aerial mycelium, light pink spores. Earthy odour.

Potato plug. Dark reddish brown growth. Very slight trace of white aerial mycelium.

Litmus milk. Completely peptonized after 1 month. No coagulation, no change in $\mathrm{pH}$ value. White fluffy growth on the bottom of the tube. Orangepink surface colonies attached to sides of test tube.

Gelatin. Slightly attacked. White fluffy growth on the bottom of tube. No surface growth.

Cellulose utilization. Attacks cellulose to a very limited degree.

Nitrate broth. No nitrite after incubation for 3-5 weeks.

Starch utilization. (1) Starch agar A: no growth. (2) Starch agar B: good growth. No diastatic activity after 3 weeks. (3) Potato agar: moderate diastatic activity. Tests for starch utilization were made with a Lugol solution.

\section{Staining properties}

Waksmania rosea is not acid-fast and is Gram-positive. It stains well with crystal violet and safranin. Preparations stained with methylene blue show: (a) some developing spores which stain entirely blue with darker 'septa' (Pl. 1, fig. 5); (b) many spores unstained except for dark blue cross-walls cutting off the spores; $(c)$ many mature spores which do not stain at all. The hyphae and sporophores do not take this stain strongly.

\section{Growth temperature}

The organism is a mesophil, growing well at $25-35^{\circ}$. It produces only a very sparse growth at $40^{\circ}$, and does not grow at all at $55^{\circ}$.

\section{Antibiotic properties}

No activity was found by cross-streak tests or in a variety of culture media incubated at $28^{\circ}$ on a rotary shaking machine and tested by the streak dilution 
method. The following test organisms were used: Candida albicans, Aspergillus niger, Saccharomyces cerevisiae, Rhizopus nigricans, Staphylococcus aureus, Sarcina lutea, Micrococcus lysodeikticus Escherichia coli.

\section{Source}

Waksmania rosea was isolated from a fallow garden soil located in Martinsville, New Jersey, U.S.A. One strain of W. rosea is deposited in the Collection of the Institute of Microbiology of Rutgers University and bears the number 3748 .

\section{DISCUSSION}

The new genus Waksmania should be included in the Streptomycetaceae. Its similarity to the other three members of the family may be summarized as follows:

(i) Streptomyces and Waksmania both produce: (a) aerial hyphae; (b) spores on the aerial hyphae only; $(c)$ some spores directly on the sporogenous hyphae; $(d)$ compact, leathery colonies that adhere to the agar; $(e)$ nonwetting spores; $(f)$ an earthy odour.

(ii) Micromonospora and Waksmania both form spores at the tip of sporophores. On some media $W$. rosea forms insoluble orange-pink pigments typical of many Micromonospora spp. and on many media on which it does not form aerial mycelium, its macroscopic aspect resembles this genus.

(iii) Thermoactinomyces and Waksmania both produce: (a) aerial mycelium; (b) some spores on sporophores; $(c)$ an earthy odour; $(d)$ non-wetting spores.

Although in certain Streptomyces spp. conidia are borne on sporophore-like branchlets, these sporophores are usually of the same diameter as the spores they bear, or occasionally when they are slightly smaller in diameter than the spores, this difference is about $0 \cdot 1-0 \cdot 2 \mu$. In Waksmania rosea, the difference between the diameter of the sporophores and the spores is usually greater than $1.0 \mu$. This more closely approaches the difference in diameter between the spore and sporophore of Micromonospora spp.

As a consequence, the following revision of the existing key to the family Streptomycetaceae is proposed:

I. Aerial (secondary) mycelium formed.

Spores formed singly (not in chains): Thermoactinomyces Tsiklinsky

Spores formed in pairs: Waksmania gen.nov.

Spores formed in chains: Streptomyces Waksman \& Henrici

II. Aerial (secondary) mycelium not formed.

Spores formed singly (not in chains): Micromonospora Ørskov

The new genus Waksmania underlines and confirms the morphological relationship of Streptomyces to Micromonospora and Thermoactinomyces. Further, it represents a link between Streptomyces and Thermoactinomycetes. Physiologically, Waksmania rosea appears to be a relatively inactive member of the Streptomycetaceae. Furthermore, the limited number of media on 
Journal of General Microbiology, Vol. 17, No. 1
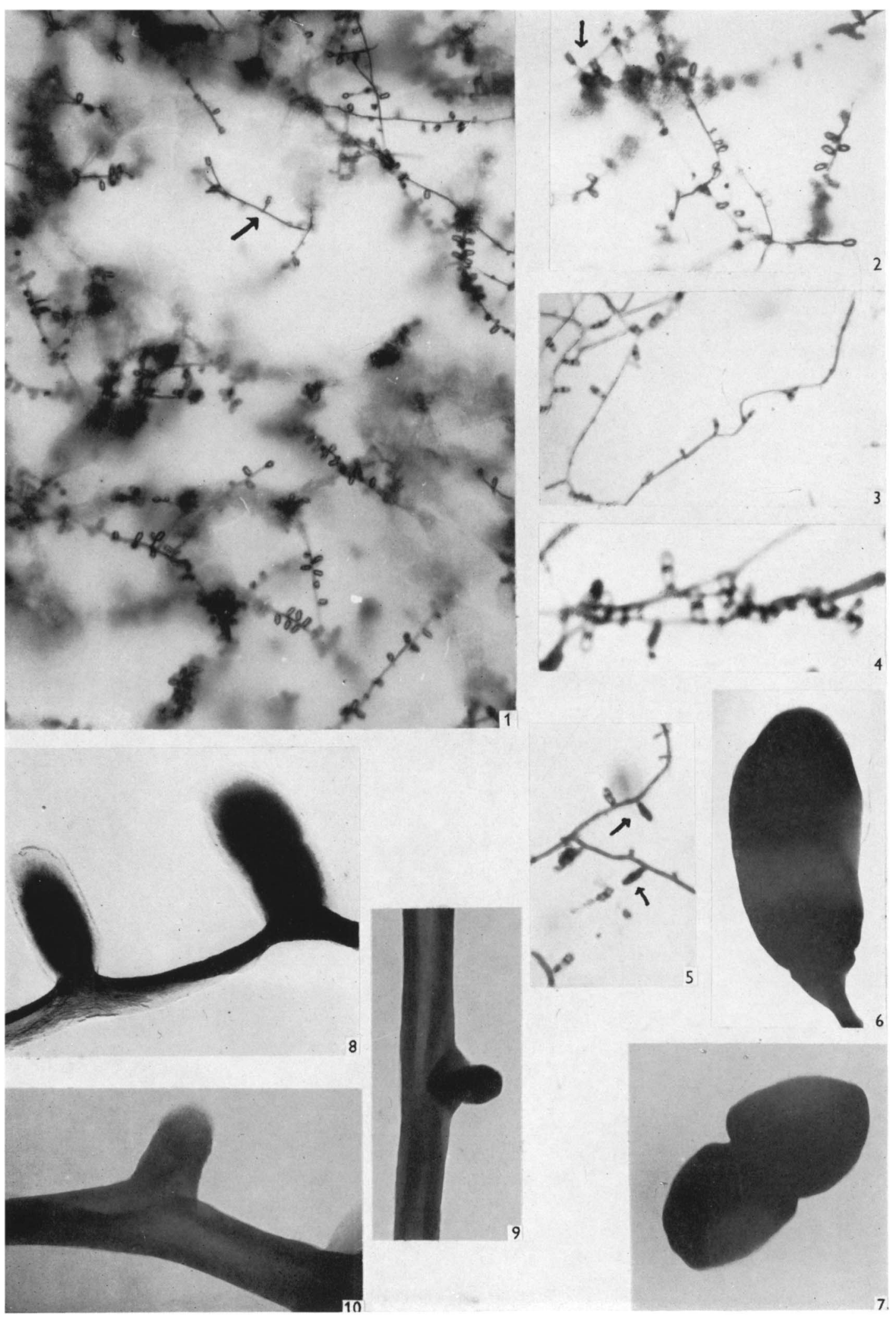

M. P. Lechevalier and H. Lechevalier-A new actinomycete genus. Plate 1 
which this organism will form spores indicates that its nutritional requirements are rather unusual. It remains to be seen whether even more radical departures from conventional methods of actinomycete isolation than those used here, will bring to light more new members of this group of important soil inhabitants.

The authors wish to acknowledge the invaluable assistance and advice of Dr Ruth E. Gordon of the Institute of Microbiology. To Miss Pauline Holbert, also of the Institute, we wish to express our sincere appreciation for taking and printing the electron micrographs. We are also greatly indebted to Dr Selman A. Waksman, Director of the Institute, for his authoritative advice on this paper.

\section{REFERENCES}

Bergey's Manual of Determinative Bacteriology (1948). 6th edition, edited by Breed, R. S., Murray, E. G. C., \& Hitchens, A. P. Baltimore: Williams and Wilkins Co.

Couch, J. N. (1939). Technic for collection, isolation, and culture of chytrids. J. Elisha Mitchell sci. Soc. 55, 208.

Couch, J. N. (1949). A group of organisms related to Actinomyces. J. Elisha Mitchell sci. Soc. 65, 315.

Couch, J. N. (1950). Actinoplanes, a new genus of the Actinomycetales. J. Elisha Mitchell sci. Soc. 66, 87.

Coucr, J. N. (1954). The genus Actinoplanes and its relatives. Trans. N.Y. Acad. Sci. 16, 315.

Coucr, J. N. (1955). A new genus and family of the Actinomycetales, with a revision of the genus Actinoplanes. J. Elisha Mitchell sci. Soc. 71, 148.

Manual of Methods for Pure Culture Study of Bacteria. Leaflet IV (1951). 10th edition, edited by Conn, H. J. and collaborators. Geneva, New York: Biotech Publications.

Waksman, S. A. (1950). The actinomycetes. Waltham, Mass.: Chronica Botanica Co.

WaKsman, S. A. \& Corke, C. T. (1953). Thermoactinomyces Tsiklinsky, a genus of thermophilic actinomycetes. J. Bact. 66, 377 .

Waksman, S. A. \& Henrici, A. T. (1943). The nomenclature and classification of the actinomycetes. J. Bact. 46, 377 .

\section{EXPLANATION OF PLATE}

Fig. 1. Aerial hyphae on culture plates viewed directly through dry objective. Arrows indicate sporophores. $\times 420$.

Fig. 2. As in fig. 1. $\times 525$.

Fig. 3. Aerial hyphae stained with methylene blue. $\times 840$.

Fig. 4. As in fig. 3. $\times 2310$.

Fig. 5. As in fig. 3. $\times 1260$. Note deeply stained immature spores at arrow.

Fig. 6. Electron micrograph of a pair of developing spores. Note cup-shaped apex of the sporophore. $\times 16,800$.

Fig. 7. Electron micrograph of detached mature spores. $\times 18,900$.

Fig. 8. Electron micrograph of young spores. $\times 11,200$.

Figs. 9 and 10. Electron micrographs of sporophores. $\times 26,600$.

(Received 7 February 1957)

After this paper was accepted for publication, a description of a thermophilic actinomycete, morphologically similar to Waksmania rosea, was published by A. Henssen in the Arch. Mikrobiol. (1957): 'Beiträge zur Morphologie und Systematik der Thermophilen Actinomyceten', 26, 373. 